\title{
Formamos professores para a educação inclusiva? Análise de publicações sobre formação de professores de Ciências/Biologia
}

Rafaela Rocha-Oliveira rafarochaios@gmail.com 0000-0001-7933-2056 Universidade Estadual

\section{Maíra Souza Machado} maira.machado1@hotmail.com 0000-0003-1219-7026 Universidade Estadual de Santa Cruz, Ihéus, Bahia, Brasil.

Maxwell Siqueira mrpsiqueira@uesc.br 0000-0002-2165-4244 Universidade Estadual de Santa Cruz, Ilhéus, Bahia, Brasil.

\section{RESUMO}

Este trabalho objetivou caracterizar um recorte do campo de estudo sobre formação de professores de Ciências e Biologia para a educação inclusiva, por meio de uma revisão da literatura, entre os anos de 1996 e 2014, em periódicos nacionais da área de ensino, disponíveis no banco de dados da CAPES/MEC. Os resultados apontam que todos os estudos sugerem a necessidade de reorganização dos cursos de formação de professores de Ciências, a fim de dar conta da perspectiva inclusiva. Constatou-se também a baixa produção sobre o tema na área e que todos os estudos são iniciais. Destacou-se a influência dos cursos de pós-graduação na formação de professores sobre o tema e a existência de um grupo de pesquisa mais atuante na Universidade Federal de Goiás. Além disso, os estudos apontam a necessidade de todo o grupo escolar estar envolvido no processo inclusivo, e a deficiência nas políticas públicas no que tange às questões específicas da educação inclusiva e a importância de compreender as concepções dos professores sobre a inclusão.
\end{abstract}

PALAVRAS-CHAVE: Educação inclusiva. Formação de professores de Ciências. Formação de professores de Biologia. 


\section{INTRODUÇÃO}

O diferente, durante muito tempo, foi rechaçado pela escola homogênea. Historicamente as condições sociais contribuíram para a segregação de alunos considerados "diferentes". Esses incluem vários grupos de minorias, como as meninas, pobres, ciganos, pessoas com deficiência etc. Contudo, "a diversidade é a essência da humanidade" (CROCHÍk, 2015, p. 24) e a escola não pode negar a natureza das coisas.

A relação dos direitos humanos com a área da educação se tornou mais consistente no Brasil, após o golpe civil e militar de 1964 (SILVA, 2015). Seguindo o raciocínio de Costa (2012), a garantia do direito à educação das minorias historicamente excluídas seria fundamental para o fortalecimento da democracia, já que seus pilares, a liberdade e a igualdade de direitos, devem ser retroalimentados com apropriação de informações e conhecimentos, frutos de uma educação crítica. Assim, a promulgação da Constituição Brasileira de 1988 (BRASIL, 1988), que teve como referência a Declaração Universal dos Direitos Humanos (ONU, 1948), destacou-se como marco nacional de defesa de direitos e no respeito à diversidade e às diferenças. Contudo, só na década de 1990, com a Declaração Mundial de Educação para Todos (UNESCO, 1990) e a posterior Declaração de Salamanca (UNESCO, 1994) foi que as políticas públicas de educação inclusiva começaram a ser estimuladas no país.

É importante salientar que o acesso à escola extrapola o ato da matrícula e implica na apropriação do saber e das oportunidades educacionais oferecidas à totalidade dos alunos com vistas a atingir as finalidades da educação, a despeito das diversidades na população escolar. Dessa forma, enfrentar o desafio da inclusão educacional é uma condição necessária para atender às expectativas de democratização da educação em nosso país, visando ao desenvolvimento e ao progresso do mesmo.

A educação inclusiva abarca amplas questões de minorias caracterizadas por fatores econômicos, religiosos, de gênero, entre outros. No Brasil, o principal alvo da educação inclusiva são os alunos com deficiência (CROCHÍK, 2015). De acordo com a Política Nacional de Educação Especial na Perspectiva da Educação Inclusiva (BRASIL, 2008, p. 15), são os considerados alunos com deficiência:

[...] àqueles que têm impedimentos de longo prazo, de natureza física, mental, intelectual ou sensorial, que em interação com diversas barreiras podem ter restringida sua participação plena e efetiva na escola e na sociedade.

O crescente número de matrículas de alunos com deficiência na rede regular de ensino nos mostra o número significativo de pessoas que estavam segregadas do ensino regular (BRASIL, 2014). Um estudo realizado por Lippe e Camargo (2009) indica que a inclusão de alunos com deficiência é um desafio atual do sistema educacional brasileiro, surgindo questões relacionadas à inclusão desses alunos. Contudo, as pesquisas, especialmente no ensino de Ciências, estão concentrando seu foco em estratégias de ensino para a inclusão, como, por exemplo, o desenvolvimento de materiais didáticos (CAMARGO; NARDI, 2007).

É indiscutível a necessidade de desenvolvimento de materiais didáticos focados na inclusão, mas, paralelo a isso, deve-se pensar na formação de professores, pois são eles os principais agentes de qualquer mudança educacional 
(BEJARANO; CARVALHO, 2003). Quando se olha para as pesquisas na área de ensino de Ciências na perspectiva da inclusão, nota-se que pouco tem sido produzido com o foco na formação de professores, representando assim, uma lacuna, principalmente na formação inicial, quando da organização dos cursos de licenciatura frente às políticas de inclusão no país (PEDROSO; CAMPOS; DUARTE, 2013).

Diante desse contexto, emerge a seguinte questão: formamos professores de Ciências/Biologia para a educação inclusiva? Para responder a essa questão, propomos uma revisão bibliográfica que visa caracterizar um recorte do campo de estudo sobre formação de professores de Ciências/Biologia ${ }^{1}$ para educação inclusiva, por meio de uma revisão da literatura publicada entre os anos de 1996 a 2014. Afinal, os periódicos são essenciais para a compreensão de uma temática, pois os artigos são estudos, normalmente empíricos, que auxiliam na construção de um conhecimento sobre um determinado problema ou temática.

\section{O desafio de formar professores de Ciências na perspectiva inclusiva}

A trajetória da formação de professores de Ciências no Brasil, assim como da educação inclusiva, trilhou um caminho de avanços e retrocessos. Para entender essa realidade, é importante considerar alguns fatos históricos que desencadearam avanços, ainda que de forma lenta, nos cursos de licenciatura do país. A pesquisa nessa área é considerada recente, visto que as reformulações no ensino de Ciências durante as décadas de 50, 60 e 70, não abrangiam mudanças consideráveis na formação docente. Atualmente, esse segmento tornou-se objeto de pesquisa acadêmica e um importante foco das políticas educacionais.

O tratamento tecnicista adotado na formação de professores até meados dos anos 80 reforçou problemas existentes no ensino de Ciências como o dogmatismo da Ciência, a descontextualização do ensino e a dicotomia teoria/prática nos cursos de formação de professores (NASCIMENTO; FERNANDES; MENDONÇA, 2010). Segundo Chassot (1995), o papel do professor se resumia a ampliar tarefas programadas e transferir informações científicas memorizadas, assim como as vivenciaram durante sua formação profissional. Na década de 60, com um aumento crescente da população escolar, ocorreu uma expansão do ensino universitário privado com a criação indiscriminada de cursos de licenciatura de curta duração. Além disso, foi dada a permissão para o exercício profissional de docentes não habilitados, fato que descaracteriza e desvaloriza a formação docente (NASCIMENTO; FERNANDES; MENDONÇA, 2010).

Com o advento de ideias construtivistas, ao menos no discurso, a imagem do professor detentor do saber foi substituída pela de orientador e mediador de experiências educativas. Assim, os professores deveriam desenvolver ações educativas respeitando as singularidades e fases do desenvolvimento cognitivo do aluno. Nesse contexto, a discussão sobre necessidades de reformulação dos cursos

\footnotetext{
Páquinal 172 foco neste estudo são as pesquisas que discutem a formação de professores de Ciências, envolvendo professores formados ou em formação do curso de Ciências Biológicas.
} 
de licenciatura entrou em pauta logo nos primeiros eventos sobre educação (NASCIMENTO; FERNANDES; MENDONÇA, 2010).

Apesar de as características individuais dos alunos começarem a serem percebidas pelos educadores como componente essencial no processo de construção de conhecimento, na prática, os alunos com deficiência ainda não eram incluídos em tal processo. Além das instituições especializadas onde havia ensino segregado, os alunos com deficiência que frequentavam a escola também eram privados de possibilidades de aprender, pois frequentavam as chamadas "classes especiais" (COSTA, 2012).

Em 1996 ocorreu a primeira publicação na legislação brasileira, baseada na Declaração de Salamanca (UNESCO, 1994), de diretrizes sobre a educação especial. No Art. 59 da Lei de Diretrizes e Bases da Educação Nacional - Lei n. 9.394/96 (BRASIL, 1996, p.17), consta que será garantido aos alunos com necessidades educacionais especiais:

III - professores com especialização adequada em nível médio ou superior, para atendimento especializado, bem como professores do ensino regular capacitados para a integração desses educandos nas classes comuns.

Contrariando a orientação de haver necessidade do ensino superior para lecionar, esse documento aceita a formação apenas no nível médio, descaracterizando a profissão docente para atuar na educação inclusiva. Com isso, a possibilidade de melhoria da educação inclusiva fica prejudicada. Isso porque uma sala de aula inclusiva demanda um professor disposto a refletir e modificar sempre que necessário suas práticas e metodologias, a fim de alcançar as particularidades da aprendizagem de cada aluno da sala, que em partes é desenvolvido na licenciatura. Nessa perspectiva, a formação continuada tem extrema importância no sentido de possibilitar uma melhoria na qualidade do ensino e proporcionar capacitação para que novas propostas educativas sejam realizadas. Segundo Pietro (2006, p. 58),

[...] os professores devem ser capazes de analisar os domínios de conhecimentos atuais dos alunos, as diferentes necessidades demandadas nos seus processos de aprendizagem, bem como, [...], elaborar atividades, criar ou adaptar materiais, além de prever formas de avaliar os alunos para que as informações sirvam para retroalimentar seu planejamento e aprimorar $\mathrm{o}$ atendimento aos alunos.

De nada adianta acessibilidade física, materiais didáticos adequados se o professor não desenvolver metodologias que garantam a inclusão do aluno com deficiência na sala de aula. Na maior parte das vezes, o professor tem o poder de decidir se o aluno será integrado ou incluído, afinal, ele deve ser o mediador na construção do conhecimento científico. Contudo, a educação inclusiva trouxe uma nova estrutura para a escola. Como mostra o estudo de Oliveira e Benite (2015), o professor deixa de ser a única figura no processo de mediação para construção do conhecimento científico, e outros profissionais, como o intérprete de Libras, o instrutor de Braille e o professor de apoio, passam a intervir no processo.

$\mathrm{Na}$ atualidade, a formação de professores no Brasil tem recebido grandes incentivos, a fim de tentar cumprir a meta da educação mundial de inclusão adequadas e façam as intervenções necessárias para atender às necessidades e os 
desafios da sociedade contemporânea. Porém, não é apenas com investimento financeiro e político que se reestrutura um processo tão abstruso quanto à formação docente. De acordo com Pletsch (2009, p. 145),

É preciso compreender que mudanças na educação para atender ao paradigma vigente de inclusão educacional dependem de diversos fatores, como, por exemplo, o contexto social, econômico e cultural em que se insere a escola, as concepções e representações sociais relativas à deficiência e, por fim, os recursos materiais e os financiamentos disponíveis à escola.

Nesse sentido, Pietro (2006) destaca que uma das principais dificuldades na inclusão escolar de um aluno com deficiência é a baixa expectativa em relação a eles, resultado da falta de capacitação docente. 0 preconceito em relação às pessoas com deficiência surge com a crença de que estes sujeitos são menos capazes. É de comum acordo entre diversos autores (PIETRO, 2006; PLETSCH, 2009; SILVA; OLIVEIRA, 2009; VILELA-RIBEIRO; BENITE, 2011a) que para a educação inclusiva ser uma realidade nas escolas brasileiras é necessária uma profunda mudança na perspectiva da formação inicial.

Mudança essa que é forçada a partir da Declaração de Salamanca (UNESCO, 1994), resolução das Nações Unidas que foi produzida na Conferência Mundial sobre Educação Especial em 1994, quando ressignificou o conceito de necessidades educacionais especiais que "passou a incluir, além das crianças [...] [com] deficiência, aquelas que estejam experimentando dificuldades temporárias ou permanentes na escola" (SANTOS, 2000, p.5). Ou seja, os cursos de formação de professores, a fim de dar conta de formar profissionais que considerem a subjetividade dos alunos na construção do conhecimento, visto que, mesmo em salas regulares sem alunos com deficiência, é preciso um ensino inclusivo que valorize, sobretudo, as especificidades individuais.

Diversas pesquisas na área (SILVA; OLIVEIRA, 2009; VILELA-RIBEIRO; BENITE, 2011a; PEDROSO; CAMPOS; DUARTE, 2013) têm em comum as falas dos professores de Ciências. Na maior parte das investigações, os docentes enfatizam o despreparo para lidar com alunos com deficiência em salas de aula e, ou conduzir aulas com práticas inclusivas. Nos primeiros anos de carreira, esse despreparo pode ser ainda maior.

Em um estudo realizado por Silva e Oliveira (2009, p. 44) com licenciados em Química, eles relatam que:

\footnotetext{
Ao ingressar nas salas de aulas, os professores novatos deparam-se com fatos que não lhes foram apresentados ao longo de seu curso de formação inicial e que advêm da prática profissional, situações complexas que ocasionam o surgimento de conflitos.
}

Nesse sentido, Camargo e Nardi (2008) afirmam que "a crise que se estabelece devido ao fato dos alunos com deficiência frequentarem a escola regular é muito bem vinda, pois questiona e movimenta as práticas educacionais consolidadas [...]" (CAMARGO; NARDI, 2008, p. 341). Por outro lado, seguindo a análise epistemológica da prática proposta por Schön (1992), essa movimentação da prática educacional só será relevante se ocorrer a partir de uma atividade cognitiva consciente do docente, capaz de gerar ou construir um novo conhecimento. Essa atitude de reflexão sobre a ação docente está diretamente relacionada com a formação recebida pelos docentes. A mudança no conhecimento dos professores 
em formação não conduz necessariamente a mudanças em sua prática, mas estreita o caminho entre reflexão/ação. Assim, Pletsch (2009, p. 148) defende que:

\begin{abstract}
[...] o atual e grande desafio posto para os cursos de formação de professores é o de produzir conhecimentos que possam desencadear novas atitudes que permitam a compreensão de situações complexas de ensino, para que os professores possam desempenhar de maneira responsável e satisfatória seu papel de ensinar e aprender para a diversidade.
\end{abstract}

Uma pesquisa realizada por Vilela-Ribeiro e Benite (2011b) aponta resultados interessantes sobre professores formadores e o currículo de cursos de licenciatura em Ciências (Biologia, Física e Química) e Matemática no estado de Goiás. Os currículos são a materialização das relações e culturas vivenciadas pelos professores que selecionam os conteúdos que devem ser trabalhados pelos novos profissionais (VILELA-RIBEIRO; BENITE, 2011b). Assim, o estudo indica que os currículos não apresentaram de forma explícita os preceitos da educação inclusiva, porém, de forma implícita, todos propõem um ensino considerando a diversidade social. Em relação aos professores formadores, eles entendem a importância da perspectiva da educação inclusiva no currículo dos cursos. Contudo, assumem a dificuldade que sentem em implementá-la, pois em geral não possuem formação ou preparo para trabalhar em tal situação.

Esse estudo indica também a necessidade de formação, inclusive dos formadores de professores para uma mudança no cenário educacional referente à inclusão escolar. Martins (2012, p. 31) aponta que:

\footnotetext{
[...] muitas instituições de ensino superior não se estruturaram no sentido de oferecer disciplinas e/ou conteúdos relativos ao tema nos seus cursos de licenciatura, enquanto que outras o fazem de maneira precária, através da oferta de disciplina eletiva, ou com carga horária reduzida, ministrada de maneira aligeirada, o que não favorece a aquisição de conhecimentos, o desenvolvimento de destrezas, habilidades e atitudes relativas ao processo de atendimento à diversidade dos educandos.
}

Esses mesmos autores tiveram como resultado de uma pesquisa empreendida com licenciandos no Campus Central na Universidade Federal do Rio Grande do Norte (UFRN) opiniões a respeito do que deveria ser feito para o aprimoramento da formação inicial de professores a respeito da educação inclusiva. Assim como na pesquisa de Theobald (2006), os futuros professores indicam que além da ampliação das disciplinas é necessário aos futuros docentes vivenciar a educação de forma inclusiva durante sua própria formação e não como um conteúdo para ser aplicado em outro ambiente.

Os professores entram nos cursos de formação com crenças pessoais a respeito do ensino, pois foram desenvolvidas a partir de suas próprias experiências como estudantes. Em geral, essas crenças permanecem sem alteração ao longo da formação inicial e acompanham os professores durante suas práticas (MARCELO, 2009). Portanto, se os futuros professores tivessem a oportunidade de vivenciar e não apenas conhecer os preceitos da educação inclusiva durante sua formação, isto possibilitaria a construção de novos conhecimentos e a reflexão sobre sua própria prática.

A Política Nacional de Educação Especial na Perspectiva da Educação Inclusiva (BRASIL, 2008, p. 14) afirma que também deve ser garantido ao aluno com necessidades educacionais especiais "formação de professores para o 
atendimento educacional especializado e demais profissionais da educação para a inclusão". A materialização dessa política, como destaca Kassar (2011), ocorre por meio de programas e ações do governo, como por exemplo, o "Programa Nacional de Formação Continuada de Professores na Educação Especial" e o de "Formação de Professores para o Atendimento Educacional Especializado", ambos na modalidade à distância. Assim, aparentemente o governo cumpre com um dos direitos dos alunos com necessidades educacionais especiais. Contudo, uma análise focada no papel da formação docente na política educacional vigente vinculada a esses programas oficiais demonstram quão retrocedente têm sido essas formações (GARCIA, 2013). Análises realizadas em materiais da Secretaria de Educação Especial (SEE) do Ministério de Educação e Cultura (MEC), utilizados como base para a formação docente, indicam a superficialidade dos conteúdos teóricos e da ênfase dada à aplicação de técnicas e recursos para diferentes tipos de necessidades educacionais especiais (idem). Assim, Garcia (2013, p. 115) afirma que "perante as necessidades de dar conta de tamanha abrangência, a qual contrasta com a restrição da formação baseada em atividades e recursos, o professor do atendimento educacional especializado se transforma em um gestor de recursos de aprendizagem."

Apesar da Política Nacional de Educação Especial na Perspectiva da Educação Inclusiva (BRASIL, 2008) também considerar a formação dos demais profissionais da educação para a inclusão, nada tem sido proposto aos cursos de formação inicial (MICHELS, 2011). Esse quadro reforça o caráter de treinamento dos programas propostos durante a formação continuada.

\section{Caminhos metodológicos}

Realizamos um levantamento dos artigos publicados em periódicos nacionais da área de Ensino, no sistema WebQualis 2013, classificados nos estratos indicativos de qualidade $\mathrm{A} 1, \mathrm{~A} 2$ e $\mathrm{B} 1$. Entre os periódicos da área de Ensino, selecionamos apenas aqueles relacionados ao ensino específico de Ciências, Biologia (área de base) e educação, desde que abrangessem artigos na área de ensino de Ciências. Essa medida eliminou a possibilidade, por exemplo, de que revistas da área médica fossem consideradas na sistematização dos dados. Posteriormente, realizou-se a busca pelas revistas selecionadas no portal de periódicos CAPES/MEC.

Para iniciar a seleção dos artigos, utilizamos como modelo as palavras-chave do estudo de Leite; Borelli e Martins (2013), acrescentando algumas outras, já que tínhamos como foco os alunos com deficiência. Assim, foi realizada a busca pelas palavras-chave: deficiência, educação especial, educação inclusiva, formação de professores de Ciências, formação de professores de Biologia e necessidades especiais. Estudos que não levam em consideração professores de Biologia não foram considerados, pois a análise é a partir da formação de professores de Ciências/Biologia. Nessa busca, quando realizada pelo site SciELO², foi usado o refinamento de busca, opção Todos os campos, que considera: título, palavra-

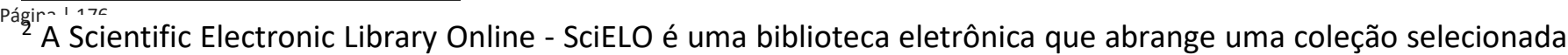
de periódicos científicos.
} 
chave, assunto e resumo. Quando o site indicado no portal de periódicos CAPES/MEC era o da própria revista, utilizamos, quando possível, o campo "conteúdo da revista", opção título, palavra-chave e resumo individualmente. Quando o site do periódico não apresentava esse campo, a revista não foi utilizada. Com ressalva, utilizamos revistas consideradas importantes para a área de ensino de Ciências, como: Alexandria (UFSC); Investigação em Ensino de Ciências (UFRGS); e a Revista Brasileira de Pesquisa em Educação em Ciências (RBPEC). Os estudos devem envolver a Biologia, como área fundamental de análise.

Foram analisados apenas artigos disponíveis publicados no período de 1996 a 2014. A data de início foi escolhida baseada na primeira publicação da Lei de Diretrizes e Bases da Educação Nacional (Lei $n^{\circ}$ 9.394/96), em que a educação especial teve um capítulo específico e suas disposições deveriam garantir a prática da educação inclusiva. Uma vez selecionados, foram realizadas leituras atentas dos artigos. A partir da leitura, analisamos os trabalhos de acordo com os seguintes aspectos: produção sobre o tema ao longo dos anos, contribuição das diferentes regiões para a pesquisa nesse campo, objetivos dos trabalhos, resultados, conclusões e informações que foram consideradas relevantes.

Desta forma, buscamos "conhecer e analisar as contribuições culturais ou científicas existentes sobre um determinado assunto" (CERVO; BERVIAN, 2002, p. 65); nesse caso, sobre as publicações voltadas para a formação de professores de Ciências/Biologia na perspectiva da educação inclusiva.

De acordo com o método detalhado anteriormente, chegou-se a seguinte lista de revistas: 
Alexandria (UFSC)

Ambiente \& Sociedade (Online)

Anais da Academia Brasileira de Ciências

Bolema. Boletim de Educação Matemática

Caderno Brasileiro de Ensino de Física (Online)

Cadernos CEDES (Impresso)

Cadernos de História da Educação (UFU. Impresso)

Ciência \& Ensino (Online)

Educação \& Linguagem (Online)

Educação e Pesquisa (USP. Impresso)

Educação em Revista (UFMG. Impresso)

Educação Matemática Pesquisa (Online)

Ensaio: Pesquisa e Educação em Ciências (Online)

Experiências em Ensino de Ciências (UFRGS)

Motriz: Revista de Educação Física (Online)

Nuances (UNESP Presidente Prudente)

Pedagogia em Foco

Pesquisa em Educação Ambiental (Online)

Pró-Posições (UNICAMP. Online)

Revista Brasileira de Educação (Impresso)

Revista Brasileira de Educação Especial

Revista Brasileira de Ensino de Ciência e Tecnologia

Revista de Ciências da Educação

Revista Educação Especial (Online)

Revista Práxis (Online)

Sociedade \& Natureza (UFU. Impresso)

Trabalho, Educação e Saúde (Online)
Ambiente \& Educação

Atos de Pesquisa em Educação (FURB)

Avaliação (UNICAMP)

Ciência \& Educação

Cadernos de Educação (UFPel)

Ciência da Informação (Impresso)

Cadernos de Pesquisa (Fundação Carlos Chagas. Impresso)

ComCiência (UNICAMP)

Educação \& Sociedade (Impresso)

Educação e Realidade

Educar em Revista (Impresso)

ETD. Educação Temática Digital

Investigações em Ensino de Ciências (UFGRS. Impresso)

Linhas (Florianópolis. Online)

Movimento (UFRGS. Impresso)

Paidéi@ (Santos)

Perspectiva (UFSC)

Práxis Educativa (UEPG. Online)

RBPG. Revista Brasileira de Pós-Graduação

Revista Brasileira de Pesquisa em Educação em Ciências

Revista Brasileira de Ensino de Física

Revista Ciências \& Ideias

Revista de Educação Publica (UFMT)

Revista Eletrônica de Educação (São Carlos)

Revista Práxis (Volta Redonda)

Trabalho \& Educação (UFMG)

Zetetiké (online) 


\section{Análise dos dados}

A lista completa do Qualis Ensino 2013 nos estratos A1, A2 e B1 apresentou um total de 227 periódicos, dos quais 100 são revistas brasileiras. Dessas, 4 estavam qualificadas como A1, 14 como A2 e 82 como B1. Entretanto, estavam disponíveis no portal de periódicos da CAPES/MEC e relacionados com a área de ensino de Ciências/Biologia, o que corresponde a 54 (54\%) revistas do total listado. Dentre essas, 4 revistas qualificadas como A1 (100\% do total selecionado), 10 como A2 (71,42\%) e 40 como B1 (48,78\%).

Os dados foram organizados de acordo com a quantidade de artigos encontrados por cada palavra-chave e sua relação com a temática formação de professores de Ciências/Biologia na perspectiva da educação inclusiva (Tabela 1). Assim, podemos observar que de um total de 5355 artigos encontrados, os 6 artigos selecionados representam aproximadamente $0,11 \%$ do total publicado. Isso demonstra como esse eixo de pesquisa se apresenta pouco expressivo nos periódicos nacionais. Por um lado, se não encontramos produções científicas voltadas para uma formação inclusiva de professores de Ciências/Biologia, provavelmente pouco tem sido realizado nesse sentido para que os professores sejam formados a partir do paradigma de inclusão escolar. Por outro, isso pode indicar a falta da divulgação de estudos sobre a formação de professores de Ciências/Biologia na perspectiva da educação inclusiva.

Tabela 1. Artigos encontrados relacionados ou não ao tema da pesquisa e a qualificação das revistas pesquisadas. NA - número de artigos encontrados; NAR - número de artigos relacionados à temática.

\begin{tabular}{l|c|c|c|c|c|c}
\multirow{2}{*}{\multicolumn{1}{c}{ Palavras-chave }} & \multicolumn{6}{c}{ Classificação das revistas } \\
\cline { 2 - 8 } & \multicolumn{2}{|c}{ A1 } & \multicolumn{2}{c}{ A2 } & \multicolumn{2}{c}{ B1 } \\
\cline { 2 - 8 } & NA & NAR & NA & NAR & NA & NAR \\
\hline Deficiência & 141 & 0 & 66 & 0 & 381 & 0 \\
\hline Educação especial & 227 & 0 & 378 & 0 & 1626 & 0 \\
\hline Educação inclusiva & 26 & 1 & 101 & 3 & 310 & 1 \\
\hline Formação de professores de Ciências & 7 & 0 & 81 & 0 & 957 & 0 \\
\hline Formação de professores de Biologia & 29 & 0 & 28 & 0 & 300 & 0 \\
\hline Necessidades especiais & 2 & 0 & 12 & 0 & 683 & 1 \\
\hline Total & 432 & 1 & 666 & 3 & 4257 & 2 \\
\hline
\end{tabular}


Como podemos visualizar na Tabela 1, o maior número de artigos encontrados sobre a temática investigada se relaciona com a palavra-chave Educação Inclusiva. Isso pode ter ocorrido pela própria definição do termo. Quando a intenção é garantir a aprendizagem do ensino de Ciências/Biologia para todos os alunos na sala de aula regular o termo correto refere-se à educação inclusiva, mesmo que para essa ser efetivada seja necessária a garantia da educação especial.

Na análise da Tabela 1, ainda percebe-se que a maior parte dos artigos encontrados se concentra nas revistas qualificadas como B1 (4257 artigos), seguidas pela revista A2 (666 artigos) e por fim pela A1 (432 artigos), fato que está relacionado a quantidade de revista de cada estrato. Já os artigos relacionados à temática investigada foram encontrados, em maior número, nas revistas qualificadas como A2 (3 artigos), seguida pelas revistas B1 (2 artigos) e A1 com apenas 1 artigo.

O primeiro artigo selecionado, "Alfabetização científica e educação inclusiva no discurso de professores formadores de professores de Ciências" (VILELARIBEIRO; BENITE, 2013), apresenta concepções de professores formadores sobre a alfabetização científica e educação inclusiva. Para tal, os autores utilizaram entrevistas e Análise de Conteúdo. Seus sujeitos foram 10 professores formadores de 4 cursos distintos (Biologia, Química, Física e Matemática) em uma IES do estado de Goiás.

O artigo "Formação de professores de Ciências em rede social: uma perspectiva dialógica na educação inclusiva” (BENITE et al., 2009) faz um relato do trabalho desenvolvido na Rede Goiana Interdisciplinar de Pesquisa em Educação Especial/Inclusiva (RPEI). Como atores desse estudo fazem parte 25 sujeitos entre professores formadores, professores em formação continuada e alunos da formação inicial.

O terceiro estudo trata do artigo "Educação inclusiva e a formação de professores de Ciências: o papel das universidades federais na capacitação de futuros educadores" (OLIVEIRA et al., 2011), em que os autores analisam opiniões de alunos da formação inicial sobre alguns cursos de licenciatura (Biologia, Química e Física) da Universidade Federal de Goiás (UFG), sobre a educação inclusiva e a ausência de disciplinas desta área. Como sujeitos participaram alunos de 2 turmas de cada curso, totalizando 122 graduandos.

O artigo selecionado em seguida foi "Rede sociais como espaço de interações discursivas sobre formação de professores de Ciências para educação inclusiva" (PEREIRA; BENITE, 2012) que se configura uma pesquisa participante. Segundo as autoras a intenção da rede social é possibilitar aos atores do estudo a reflexão sobre suas concepções, com fundamentação na teoria. Como sujeitos desse estudo também fizeram parte professores formadores, professores em formação continuada e alunos da formação inicial, contabilizando 25 sujeitos.

Pinheiro e Rampelloto (2012), por sua vez, publicaram o artigo "A educação ambiental sob um enfoque didático de ensino para alunos com necessidades educacionais especiais", que também foi selecionado. Esse estudo analisou as concepções de 59 sujeitos de um curso de pós-graduação sobre o ensino de educação ambiental voltado para alunos com necessidades educacionais especiais.

Por fim, o último artigo selecionado foi "Professores formadores de professores de Ciências: o que influencia suas concepções sobre inclusão? " 
(VILELA-RIBEIRO; BENITE, 2011a). Esse estudo analisou as concepções de 37 docentes dos cursos de Ciências Biológicas (19), Física (6), Matemática (5) e Química (7) na UFG sobre educação inclusiva e diversidade. Como instrumento de coleta de dados foram utilizados o questionário e a análise foi quantitativa.

Conforme consta na Tabela 2, identificamos que as publicações sobre formação de professores de Ciências e, ou Biologia com foco na educação inclusiva se limita aos anos de 2009, 2011, 2012 e 2013. Em outros trabalhos, como o de Silva et al (2013), no qual foi realizada uma análise de publicações sobre Educação Especial nos encontros Nacionais de Pesquisa em Educação em Ciências (ENPEC), os dados não são muito distintos. Apesar desse trabalho investigar a Educação Especial considerando vários focos temáticos (Formação de professores; Ensino e aprendizagem; Materiais didáticos; Levantamento bibliográfico; e Novas Tecnologias de Informação e Comunicação), que não são considerados neste trabalho, a primeira publicação só foi registrada no ano de 2001, há mais de uma década. Ou seja, mesmo quando se amplia o estudo, a quantidade de publicações é pequena, indicando a escassez de estudos produzidos sobre o tema. Isso pode ser fruto da falta de interesse em publicar os estudos, ou que pouca mudança tem sido proposta para a formação de professores na perspectiva da educação inclusiva.

Tabela 2. Relação de artigos analisados das revistas científicas, sua classificação, ano de publicação, autores e a Instituição de Ensino Superior (IES).

\begin{tabular}{llclc}
\hline Qualis & Revista & Ano & Autores & IES \\
\hline A1 & Ciência \& Educação (UNESP) & 2013 & VILELA-RIBEIRO; BENITE & UFG \\
A2 & Ver. Bras. Pesq. em Ed. Em Ciências & 2009 & BENITE; et al & UFG \\
A2 & Revista Ensaio & 2011 & OLIVEIRA; et al & UFG \\
A2 & Investigações em Ensino de Ciências & 2012 & PEREIRA; BENITE & UFG \\
B1 & Ambiente \& Educação & 2012 & PINHEIRO; RAMPELLOTO & UFSM \\
B1 & Alexandria & 2011 & VILELA-RIBEIRO; BENITE & UFG \\
\hline
\end{tabular}

Outro aspecto que buscamos analisar refere-se à origem dos artigos analisados. Desse modo, foi verificado que a região brasileira que mais contribui com a pesquisa sobre a formação de professores de Ciências para educação inclusiva foi a Centro-oeste. Cinco dos seis artigos selecionados são oriundos da Universidade Federal de Goiás (UFG), GO. É interessante apontar que dois desses artigos, o que corresponde a $33,33 \%$ do total analisado, são das autoras VilelaRibeiro e Benite (2011a; 2013), sendo que em 4 dos 6 artigos analisados, a autora Anna Maria Canavarro Benite se apresenta como pesquisadora. Apenas 1 (16\%) dos trabalhos analisados é oriundo da Universidade Federal de Santa Maria (UFSM), região Sul do país. Nas regiões Sudeste, Nordeste e Norte não foram identificadas publicações sobre o assunto.

No que diz respeito à maior parte das produções serem oriundas UFG, isto demonstra que essa instituição e seus respectivos pesquisadores primaram por 
tentar entender o fenômeno da educação inclusiva no Ensino de Ciências, de forma que essas pesquisas podem ser referências importantes para os próximos estudos sobre essa temática no Brasil.

Com esse resultado, podemos perceber a defasagem da publicação de pesquisa no país versus as políticas públicas de educação. Há mais de uma década que se discute e se publicam Diretrizes da Educação Nacional, almejando a cultura da inclusão educacional no Brasil. Em contrapartida, não estão formando professores de Ciências qualificados para o ensino inclusivo, o que, segundo VilelaRibeiro e Benite (2011b, p. 128), "[...] a priori, parece ser a melhor opção para sanar as deficiências profissionais encontradas na educação básica no que diz respeito a esse assunto".

Na Tabela 3, os objetivos dos artigos foram transcritos de acordo com a sequência encontrada na lista de periódicos nacionais da área de Ensino, no sistema WebQualis 2013. 


\begin{tabular}{|c|c|c|}
\hline Qualis & Ano & Objetivo \\
\hline A1 & 2013 & $\begin{array}{l}\text { Analisar concepções sobre alfabetização científica e educação inclusiva } \\
\text { nos discursos de professores formadores de professores de ciências } \\
\text { (Biologia, Física, Matemática e Química). }\end{array}$ \\
\hline$A 2$ & 2009 & $\begin{array}{l}\text { Caracterizar o movimento de constituição da Rede Goiana Interdisciplinar } \\
\text { de Pesquisa em Educação Especial/Inclusiva (RPEI), intencionando } \\
\text { compreender o contexto das interações sociais que caracterizam a } \\
\text { estrutura própria em que se constitui a Rede Social: quem são seus atores } \\
\text { e quais suas ligações; seus objetivos; a metodologia de trabalho. }\end{array}$ \\
\hline A2 & 2011 & $\begin{array}{l}\text { Analisar opiniões e expectativas de graduandos dos cursos de Física, } \\
\text { Química e Biologia (licenciatura), no que diz respeito ao preparo que os } \\
\text { futuros educadores vêm recebendo nas universidades federais para lidar } \\
\text { com alunos portadores de NEE's, além de discutir propostas de inserção } \\
\text { de disciplinas que visem à socialização da educação inclusiva nos } \\
\text { currículos das licenciaturas. }\end{array}$ \\
\hline$A 2$ & 2012 & $\begin{array}{l}\text { Analisar interações discursivas produzidas dentro de uma rede social, a } \\
\text { Rede Goiana Interdisciplinar de Pesquisa em Educação Especial/Inclusiva } \\
\text { (RPEI). }\end{array}$ \\
\hline B1 & 2012 & $\begin{array}{l}\text { Questionar os sujeitos pesquisados, as concepções de ensino em } \\
\text { educação ambiental voltadas a alunos com necessidades educacionais } \\
\text { especiais, tendo em vista a inserção desse tema em sua formação. }\end{array}$ \\
\hline B1 & 2011 & $\begin{array}{l}\text { Perceber as concepções dos docentes dos cursos de Ciências Biológicas, } \\
\text { Física, Matemática e Química da Universidade Federal de Goiás-Campus } \\
\text { Jataí (UFG/CJ) sobre inclusão e formação de professores para a } \\
\text { diversidade. }\end{array}$ \\
\hline
\end{tabular}


Por meio da leitura dos estudos e de seus objetivos, podemos notar que metade dos artigos investigam a formação inicial de professores e a outra metade a formação continuada de professores. Também observamos que três dos seis artigos analisados focam a investigação nas concepções de seus sujeitos da pesquisa sobre o tema. Um deles investiga as concepções de licenciandos para uma posterior análise dos cursos de formação de professores. Outros dois estudos versam sobre a concepção dos docentes de cursos de licenciatura e sinalizam que talvez seja por lá que o paradigma da inclusão escolar deve ser iniciado (VILELARIBEIRO; BENITE, 2011a).

Compreender as concepções dos professores é um aspecto importante da formação, pois, como destacam Pórlan, Rivero e Martín (1997), as concepções dos professores precisam ser mapeadas, pois podem originar obstáculos para práticas inovadoras ou diferenciadas em sala de aula.

Também esteve presente como tema de investigação nos objetivos dos artigos selecionados a Rede Goiana Interdisciplinar de Pesquisa em Educação Especial/Inclusiva (RPEI), que se constitui como uma alternativa para formação inicial e continuada de professores de Ciências para inclusão escolar. Esse projeto conta com a participação dialógica entre três esferas da sociedade: acadêmica (UFG); política/gestora (Secretária de Educação do Estado de Goiás); e a comunidade (Associação de Surdos de Goiânia). Partindo do pressuposto de que "somos constituídos, enquanto sujeitos em formação, nas interações sociais" (VYGOTSKY, 2000 apud BENITE, et al., 2009, p. 3) o RPEl propõe um grupo de discussões conceituais que busca promover reflexões sobre a prática docente. Como fruto desse trabalho, no recorte deste estudo, temos dois artigos publicados que buscaram caracterizar e analisar essa experiência.

De forma geral, percebemos, por meio dos objetivos, que todos os estudos são investigações iniciais sobre a educação inclusiva e formação de professores de Ciências e, ou Biologia.

O resultado da pesquisa nos diferentes estudos aponta alguns discursos e situações corriqueiras percebidas pelos professores. Como, por exemplo, o conhecimento raso sobre o tema inclusão por grande parte dos docentes. Essa situação, resultado de uma formação precária em termos de diversidade, traz consigo a insegurança para efetivar esse novo paradigma. Além do mais, "para haver uma implantação real de práticas inclusivas na universidade é preciso repensar a preparação de seus professores, de maneira que eles conheçam o assunto e saibam se posicionar crítica e reflexivamente no ensino" (VILELARIBEIRO; BENITE, 2011a). A RPEI, como espaço de formação em rede, traz a possibilidade de compartilhar experiências e conhecimentos que estimulem a reflexão e posicionamento crítico.

Outro discurso encontrado é sobre a alienação das políticas públicas em relação à realidade de alguns alunos com deficiências. É sabido que o desafio da inclusão é lançado a todos continuamente com a presença de alunos com deficiência nas escolas e universidades. Porém, "[...] muitos aspectos relativos às condições severas, funcionais e cognitivas, apresentadas por muitos desses alunos, os quais demandam atenção específica e constante, acabam não sendo relevantes diante das políticas públicas" (PINHEIRO; RAMPELLOTO, 2012, p. 58). As concepções dos professores indicam que, em algumas situações, a prática na escola está submetida a políticas públicas baseadas em teorias que estão distantes 
da realidade. Segundo os autores Pinheiro e Rampelloto (2012, p. 58), "[...] no intuito de atacar, em passo acelerado, a pressões sociais e legais, não se revê quais as melhores formas de preservação educacional e moral desses indivíduos".

O estudo de Vilela-Ribeiro e Benite (2011) também traz como resultado a influência científica e política dos cursos de pós-graduação na constituição do professor. As autoras entendem que "[...] tais cursos de pós-graduação [têm] maior influência na percepção dos professores sobre inclusão, uma vez que pesquisar sobre a educação exige estudo e reflexão crítica sobre os temas escolhidos [...]" (VILELA-RIBEIRO; BENITE, 2011a, p. 142).

De maneira ampla, esses estudos traçam um panorama inicial dos cursos de formação de professores de Ciências e, ou Biologia, evidenciando o olhar do professor na instabilidade causada pelo paradigma da educação inclusiva no ensino de Ciências. Os resultados desses estudos sinalizam por onde podemos iniciar reflexões e ações, além de apontar possíveis caminhos para o aprofundamento de pesquisas na área.

Com base nas conclusões dos estudos, as análises indicam uma formação inicial deficitária no que tange à formação de professores para uma educação inclusiva. Além disso, é reiterado que os professores formadores das IES entendem a importância da perspectiva inclusiva, mas não atuam nessa direção. Em geral, atribui-se esse resultado à falta de formação e de vivência dos formadores de professores.

Todos os estudos sugerem a necessidade de reorganização dos cursos de formação de professores de Ciências, a fim de dar conta da perspectiva inclusiva. Além disso, apontam a necessidade de todo o grupo escolar estar envolvido no processo inclusivo. Os trabalhos sobre a RPEl indicam um possível caminho para movimentar os cursos de formação, que não dão conta de formar indivíduos que atuem na diversidade e garantam a Educação para Todos.

\section{O que a análise dos periódicos nos indica}

Para realização do estudo descrito, foram pesquisados 54 periódicos na área de Ensino que estavam disponíveis no portal de periódicos da CAPES/MEC. Nas revistas disponíveis, encontramos 5355 artigos com as palavras-chave deficiência, educação especial, educação inclusiva, formação de professores de Ciências, formação de professores de Biologia e necessidades especiais. Somente 6 artigos foram selecionados, pois os demais não versavam sobre a temática delimitada para a pesquisa, evidenciando a baixa e preliminar produção sobre o tema na área. Destacamos que as publicações se concentram nos últimos 4 anos. Esses artigos foram publicados com mais frequência em periódicos classificados como A2, na área de Ensino, conforme a avaliação da Capes.

É importante salientar que, como todo estudo, este também apresenta limites, já que se trata de um levantamento com tema bastante específico, o da formação de professores de Ciências e Biologia focado na educação inclusiva. Em geral, para incluir alunos com deficiência é necessário utilizar recursos específicos que possam explorar diferentes caminhos para a construção do conhecimento. As aulas devem ser antecipadamente planejadas para que adaptações necessárias 
sejam feitas. $O$ professor pode e deve desenvolver recursos didáticos específicos no seu conteúdo (SÁ, 2011). Porém, o conhecimento didático não pode estar desvinculado do conhecimento pedagógico. A análise e reflexão da própria ação são importantes instrumentos para a transformação da prática do professor (SCHÖN, 1992). Nesse sentido, identificamos uma precária formação dos professores, tanto inicial quanto continuada, sobre o tema. Os ganhos políticos, socioculturais e econômicos conquistados pelos Direitos Humanos, ao longo do tempo, têm promovido mudanças nos paradigmas educacionais que resultam em uma nova realidade na escola regular. Contudo, os estudos investigados indicam que muito precisa ser feito para termos uma escola capaz de lidar com a diversidade, principalmente no que tange às políticas públicas sobre questões específicas da educação inclusiva.

Outro aspecto importante que emergiu da análise é que grande parte dos estudos está voltado para a investigação das concepções dos professores sobre a educação inclusiva. Isso indica que os pesquisadores estão preocupados em entender o que os professores compreendem da educação inclusiva para, possivelmente, nortear futuras ações voltadas para perspectiva inclusiva.

Os estudos analisados também destacam a influência positiva dos cursos de pós-graduação na formação de professores de Ciências e Biologia sobre a educação inclusiva. Isso pode ser percebido na atuação do grupo de pesquisa da Universidade Federal de Goiás, responsável por cinco artigos selecionados. Além de trazer como proposta a organização de redes compostas pelos diversos setores que atuam na educação inclusiva, a produção de conhecimento científico tem feito parte desse projeto.

Consideramos que pesquisas desse tipo servem de embasamento para futuras produções, situando a formação de professores de Ciências e, ou Biologia na perspectiva da educação inclusiva, elucidando o que, de fato, tem sido produzido e investigado. Com uma produção mais expressiva de pesquisas nessa área, talvez seja possível trilharmos os caminhos de uma formação de professores de Ciências e Biologia que contemple esse novo público agora presente de forma significativa na rede básica de ensino. 


\title{
Do we train teachers to inclusive education? Publications of analysis on teacher education in science/biology
}

\begin{abstract}
Thus, this study focuses on characterizing the field of study about Science and Biology teacher education for inclusive education, through a literature review between 1996 and 2014, in national education journals available from bank of data of CAPES / MEC. It was also verified the low production on the subject in the area and that all the studies are initial. The influence of postgraduate courses on teacher education on the subject and the existence of a more active research group at the Universidade Federal de Goiás was highlighted. The results show that all studies suggest the need for reorganization of the curriculum for science teacher education courses in order to realize the inclusive perspective. Also, data indicate the need for the entire school group being involved in the inclusive process and the deficiency in public policies regarding the specific issues of inclusive education and the importance of understanding teachers' conceptions of inclusion.
\end{abstract}

KEYWORDS: Inclusive education. Science teacher education. Biology teacher education. 


\section{REFERÊNCIAS}

BEJARANO, N. R. R; CARVALHO, A. M. P. Tornando-se professor de Ciências: crenças e desafio. Ciência \& Educação, v. 9, n. 1, p. 1-15, 2003.

BENITE, A. M. C.; PEREIRA, L. L. S.; BENITE, C. R. M.; PROCÓPIO, M. V. R.; FRIEDRICH, M. Formação de professores de Ciências em rede social: uma perspectiva dialógica na educação inclusiva. Revista Brasileira de Pesquisa em Educação em Ciências, v. 9, n³ 3, 2009.

BRASIL. Constituição da República Federativa do Brasil. Brasília: Senado Federal, 1988.

BRASIL. Lei no 9.394, de 20 de dezembro de 1996. Lei de Diretrizes e Bases da Educação Nacional. Estabelece as diretrizes e bases da educação nacional. Diário Oficial [da] República Federativa do Brasil, Brasília, 23 dez. 1996. Seção 1. Disponível em: <http://www.planalto.gov.br/ccivil_03/Leis/L9394.htm>. Acesso em: mar. 2015.

BRASIL. Ministério da Educação. Instituto Nacional de Estudos e Pesquisas Educacionais Anísio Teixeira (INEP). Diretoria de Estatísticas Educacionais. Nota Técnica № 020/2014. Brasília, 21 de novembro de 2014.

BRASIL. Política Nacional de Educação Especial na Perspectiva da Educação Inclusiva. Brasília: Ministério da Educação, Secretaria de Educação Especial, 2008. Disponível em: $<$ http://portal.mec.gov.br/arquivos/pdf/politicaeducespecial.pdf>. Acesso em: Jun. 2015.

CAMARGO, E. P.; NARDI, R. Panorama geral das dificuldades e viabilidades para a inclusão do aluno com deficiência visual em aulas de ópticas. Alexandria Revista de Educação em Ciências e Tecnologia, V.1, no 2, p. 81-106, 2008.

CAMARGO, E. P.; NARDI, R.. Planejamento de Atividades de Ensino de Física para alunos com deficiência visual: dificuldades e alternativas. Revista Electrónica de Enseñanza de las Ciencias, v. 6, n. 2, p. 378-401, 2007.

CERVO, A. L. BERVIAN, P. A. Metodologia científica. 5.ed. São Paulo: Prentice Hall, 2002. 
COSTA, V. A. Formação de professores e educação inclusiva frente às demandas humanas e sociais: para quê? In: MIRANDA, T. G.; GALVÃO FILHO, T. A. (Orgs.). O professor e a educação inclusiva: formação, práticas e lugares. Salvador: EDUFBA, 2012, p. $89-110$.

CROCHÍK, J. L. Educação inclusiva, subjetividade, preconceito e direitos humanos: qual sua relação? In: SILVA, A. M. M.; COSTA, V. A. (Orgs.). Educação inclusiva e direitos humanos: perspectivas contemporâneas. São Paulo: Cortez, 2015, p. 23 $-53$.

GARCIA, R. M. C. Política de educação especial na perspectiva inclusiva e a formação docente no Brasil. Revista Brasileira de Educação, Rio de Janeiro, v. 18, n. 52, p. 101-239, 2013. Disponível em: < http://www.scielo.br/pdf/rbedu/v18n52/07.pdf>. Acesso em: Jun. 2015.

KASSAR, M. C. M. Educação especial na perspectiva da educação inclusiva desafios da implantação de uma política nacional. Educar em Revista, Curitiba, Brasil, n 41, p. 61 - 79. 2011.

LEITE, L. P.; BORELLI, L. M.; MARTINS, S. E. S. O. Currículo e deficiência: análise de publicações brasileiras no cenário da educação inclusiva. Educação em Revista, Belo Horizonte, v. 29, no 1, 63-92, 2013.

LIPPE, E. M. O; CAMARGO, E. P. Análise da formação inicial de professor de Ciências e Biologia frente ao desafio da inclusão escolar: uma questão curricular. II Congresso Brasileiro de Educação. Bauru: Unesp, v.1, 2009.

MARCELO, C. A identidade docente: constantes e desafios. Revista Brasileira de Pesquisa sobre Formação Docente, v. 1, n 1, 109-131, 2009.

MARTINS, L. A. R. Reflexões sobre formação de professores com vistas à educação inclusiva. In: MIRANDA, T. G.; GALVÃO FILHO, T. A. (Orgs.). O professor e a educação inclusiva: formação, práticas e lugares. Salvador: EDUFBA, 2012, p. $25-38$. Disponível em: <http://www.ufsm.br/revistaeducacaoespecial>. Acesso em: Jun. 2015. 
NASCIMENTO, F.; FERNANDES, H. L.; MENDONÇA, V. M. O ensino de ciências no Brasil: história, formação de professores e desafios atuais. Revista HISTEDBR Online, Campinas, n.39, p. 225-249, 2010.

OLIVEIRA, M. L.; ANTUNES, A. M.; ROCHA, T. L.; TEIXEIRA, S. M. Educação inclusiva e a formação de professores de ciências: o papel das universidades federais na capacitação de futuros educadores. Revista Ensaio, Belo Horizonte, v. $13, n^{\circ} 3$, p. 99-117, 2011.

OLIVEIRA, W. D.; BENITE, A. M. C. Estudos sobre a relação entre o intérprete de LIBRAS e o professor: implicações para o ensino de ciências. Revista Brasileira de Pesquisa em Educação em Ciências, v. 15, n 3, p. 597 - 626, 2015.

ONU. Declaração Universal dos Direitos Humanos, 1948. Disponível em: <http://www.ohchr.org/EN/UDHR/Documents/UDHR_Translations/por.pdf>.

PEDROSO, C. C. A.; CAMPOS, J. A. P. P.; DUARTE, M. Formação de professores e educação inclusiva: análise das matrizes curriculares dos cursos de licenciatura. Educação Unisinos. v.17, n¹, p.40-47, 2013.

PEREIRA, L. L. S.; BENITE, A. M. C. Redes sociais como espaço de interações discursivas sobre formação de professores de Ciências para a educação inclusiva. Investigações em Ensino de Ciências, v. 17, n³ 3, p. 615 - 639, 2012.

PIETRO, R. G. Atendimento escolar de alunos com necessidades educacionais especiais: um olhar sobre as políticas públicas de educação no Brasil. In: MANTOAN, T. E.; PIETRO, R. G.; ARANTES, V. A. (Org.). Inclusão escolar: pontos e contrapontos. São Paulo: Summus, 2006. p. 31-69.

PINHEIRO, D.; RAMPELLOTO, E. M. A educação ambiental sob um enfoque didático de ensino para alunos com necessidades educacionais especiais. Ambiente \& Educação, Rio Grande, v. 17, no2, p. 53-65, 2012.

PLETSCH, M. D. A formação de professores para a educação inclusiva: legislação, diretrizes políticas e resultados de pesquisas. Educar, Curitiba, n³3, p.143-156, 2009.

PÓRLAN, A. R.; RIVERO, G. A.; MARTíN, D. P. R. Conocimento profesional y epistemología de los profesores I: teoría, métodos e instrumentos. Enseñanza de Las Ciencias, v. 15, no 2, 1997. p. 155-171. 
SÁ, E. D. de. Atendimento Educacional Especializado para alunos cegos e com baixa visão. In: MANTOAN, T. E. O desafio das diferenças nas escolas. 4a Edição. Petrópolis, RJ: Vozes, 2011. p. 111-121.

SANTOS, M. P. Educação Inclusiva e a Declaração de Salamanca: Consequências ao Sistema Educacional Brasileiro. Integração, Ano 10, no 22, p. 34 - 40. 2000.

SCHÖN, D. A. Formar professores como profissionais reflexivos. In: NÓVOA, A. Os professores e sua formação, Lisboa: Dom Quixote, 1992.

SILVA, A. M. M. A formação docente na perspectiva da educação inclusiva e a relação com os direitos humanos. In: SILVA, A. M. M.; COSTA, V. A. (Orgs.). Educação inclusiva e direitos humanos: perspectivas contemporâneas. São Paulo: Cortez, 2015, p. 91 - 116.

SILVA, C. S; OLIVEIRA, L. A. A. Formação inicial de professores de Química: formação específica e pedagógica. In: NARDI, R. (Org.). Ensino de ciências e matemática, I: temas sobre a formação de professores. São Paulo: Cultura Acadêmica, 2009.

SILVA, L. D. S.; SILVA, I. M.; DIAS, V. B.; SIQUEIRA, M.; MASSENA, E. P.; FRANÇA, S. S.; SANTOS, A. S.; MELO, J. S.; COSTA, M. R.; COTIAS, V. L. Tendências das pesquisas em Educação Especial no Ensino de Ciências: o que o ENPEC e os periódicos nos indicam? Atas do IX Encontro Nacional de Pesquisa em Educação em Ciências - IX ENPEC. Águas de Lindóia, SP. 10 a 14 de Novembro de 2013.

THEOBALD, I. M. Docência e diversidade nas licenciaturas - reflexões de futuros docentes em matemática e física. Revista Iberoamericana de Educación, no 40/4, p. 1-6, 2006.

UNESCO. Declaração de Salamanca e suas linhas de ação sobre necessidades educativas especiais. Brasília, 1994. Disponível em:

<portal.mec.gov.br/seesp/arquivos/pdf/Salamanca.pdf>. Acesso em: dez. 2015.

UNESCO. Declaração Mundial de Educação para Todos: satisfação das necessidades básicas de aprendizagem. Jomtien, 1990. Disponível em: <http://unesdoc.unesco.org/images/0008/000862/086291por.pdf>. Acesso em: jan. 2016. 
VILELA-RIBEIRO, E. B.; BENITE, A. M. C. Professores formadores de professores de Ciências: o que influencia suas concepções sobre inclusão? Alexandria, v. $4, n^{\circ} 2$, p. 127-147, 2011a.

VILELA-RIBEIRO, E. B.; BENITE, A. M. C. Sobre a educação inclusiva na formação de professores de Ciências: a tessitura dos currículos praticados. Acta Scientiarum Education, Maringá, v. 33, n², p. 239-245, 2011b.

Recebido: 2015-05-08

Aprovado: 2016-12-01

DOI: $10.3895 /$ rbect.v10n2.3784

Como citar: ROCHA-OLIVEIRA, R.; MACHADO, M. S.; SIQUEIRA, M. Formamos professores para a educação inclusiva? Análise de publicações sobre formação de professores de Ciências/Biologia. Revista Brasileira de Ensino de Ciência e Tecnologia, v. 10, n. 2, 2017. Disponível em:

<https://revistas.utfpr.edu.br/rbect/article/view/3784>. Acesso em: xxx.

Correspondência:

Direito autoral: Este artigo está licenciado sob os termos da Licença Creative Commons-Atribuição 4.0 Internacional.

(c) (1) 